\title{
Introducing antiretroviral (ARV)-based prevention products for women: A guide to strategic decisionmaking and planning
}

Population Council

Follow this and additional works at: https://knowledgecommons.popcouncil.org/departments_sbsr-hiv

Part of the Community Health and Preventive Medicine Commons, Demography, Population, and Ecology Commons, Family, Life Course, and Society Commons, and the International Public Health Commons How does access to this work benefit you? Let us know!

\section{Recommended Citation}

Population Council. 2015. "Introducing antiretroviral (ARV)-based prevention products for women: A guide to strategic decisionmaking and planning." New York: Population Council. 
INTRODUCING

ANTIRETROVIRAL (ARV)-BASED

PREVENTION PRODUCTS

FOR WOMEN

A GUIDE TO STRATEGIC DECISIONMAKING AND PLANNING
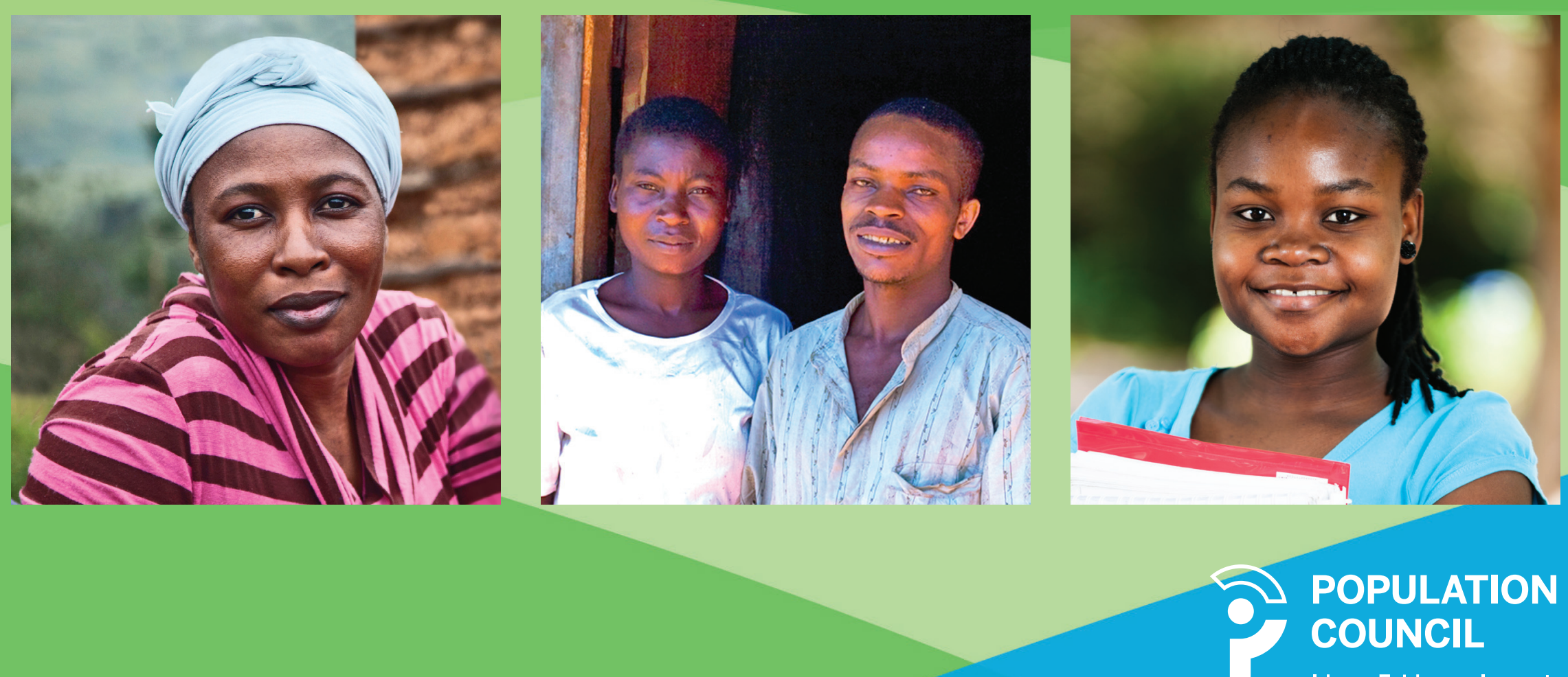


\section{POPULATION \\ 7 COUNCIL \\ Ideas. Evidence. Impact.}

The Population Council confronts critical health and development issues-from stopping the spread of HIV to improving reproductive health and ensuring that young people lead full and productive lives. Through biomedical, social science, and public health research in 50 countries, we work with our partners to deliver solutions that lead to more effective policies, programs, and technologies that improve lives around the world. Established in 1952 and headquartered in New York, the Council is a nongovernmental, nonprofit organization governed by an international board of trustees.

\section{Population Council}

One Dag Hammarskjold Plaza

New York, New York 10017 USA

popcouncil.org

This toolkit is made possible by the generous support of the American people

USADD through the United States Agency for International Development (USAID).

The contents are the sole responsibility of the Population Council and do not necessarily reflect the views of USAID or the United States government.

Suggested citation: Population Council. 2015. “Introducing Antiretroviral (ARV)-Based Prevention Products for Women: A Guide to Strategic Decisionmaking and Planning." New York.

The photographs on the cover are used for illustrative purposes only; they do not imply any particular health status on the part of any person who appears in the images. 


\section{Contents}

$\begin{array}{ll}\text { Introduction } & 1\end{array}$

$\begin{array}{ll}\text { Guiding Principles } & 1\end{array}$

About this Toolkit $\quad 2$

How to Use this Toolkit 3

$\begin{array}{ll}\text { Getting Started } & 4\end{array}$

Module 1: Landscape Analysis

Module 2: Key Opinion Leader and Decisionmaker Discussion Guide 9

Module 3: Program Planning Guide 13

$\begin{array}{ll}\text { Appendixes } & 17\end{array}$

Appendix 1: Key Guidelines and Reference Materials 18

Appendix 2: Sample Agenda: Program Planning for Tenofovir Gel Introduction 23

Appendix 3: A Checklist for Service-Delivery Readiness 


\section{Acknowledgments}

This toolkit was developed by a Population Council team that was led by Martha Brady and included Barbara Friedland, Saiqa Mullick, and Avina Sarna. Additional input was provided by Population Council consultants Lynn Bakamjian, Heidi Jones, and Elizabeth McGrory. We thank Joyce Altman and Mike
Vosika of the Population Council's Office of Publications and Creative Services for the editing and design of this document, and Virginia Kallianes for administrative coordination. We gratefully acknowledge the key opinion leaders in India and Zimbabwe whose insights were invaluable in the creation of this toolkit. 


\section{Introduction}

As evidence mounts that antiretrovirals (ARVs) are effective for HIV prevention, policymakers and program managers will need to determine whether and how best to introduce specific products into health care systems. Determining the most appropriate users within a particular country will depend on the overall context, the nature of the HIV epidemic within the country, and the opportunities available to reach and serve HIV-negative women with ARV-based prevention products and services.

This toolkit was developed by the Population Council for use by governments, organizations, and donors that are in a position to support or add new HIV-prevention products into programs. The toolkit was designed to help identify strategic opportunities for providing ARV-based products to women. The most effective mix of program entry points and delivery channels will vary from country to country. Similarly, the particular role a given product will play in a country will depend on a range of epidemiological, health system, and economic factors.

\section{GUIDING PRINCIPLES}

This toolkit was developed based on the belief that women should have access to a wide range of options to prevent HIV and have the ability to choose those that best meet their needs. The following principles guided the creation of this document:

- Equitable access to HIV prevention must take into account the specific populations at risk. In many countries, women and girls are at increased vulnerability for HIV/AIDS given gender inequality, discrimination, and stigma, and have few tools to mitigate their risk.

- Women-initiated technologies are needed, given women's widespread vulnerability to HIV infection and the underlying social and normative factors that contribute to their limited control over sexual relations.

- New HIV-prevention products for women should complement existing prevention strategies and products, including male and female condoms.

- The introduction of new products should be coordinated and integrated with other services and programs to capitalize on existing infrastructure and program efforts. 


\section{About this Toolkit}

Introducing Antiretroviral (ARV)-Based Prevention Products for Women assists users in planning for the introduction of new HIV-prevention products (and accompanying services) in a manner that supports high-quality, integrated services. It guides policymakers and program managers through a systematic process of assessing the role and potential impact of a new product into their programs while considering the feasibility of introducing it in specific settings.

This toolkit focuses on facility-based services; provision of ARV-containing products will likely be prescription-only at first and require capacity for HIV testing and monitoring. It guides users through a series of considerations to identify potential barriers and assets within the service setting, which should be considered in program design and planning. This process will result in a programmatic action plan for effective product introduction in a manner that supports individuals' rights and promotes quality services.
NOTE: This document is not designed as a detailed assessment tool. Numerous assessment guides and programming tools have been developed to design HIV/AIDS programs and services and to support integration of HIV/AIDS services into existing programs. (See Appendix 1 for a list of selected program and policy tools.) Most of these tools are geared toward large-scale facility assessment and, therefore, require more time and resources to implement than the process proposed here. Should it be required, these more in-depth assessment tools can be used to follow up and complement the action planning resulting from the use of this toolkit. 


\section{HOW TO USE THIS TOOLKIT}

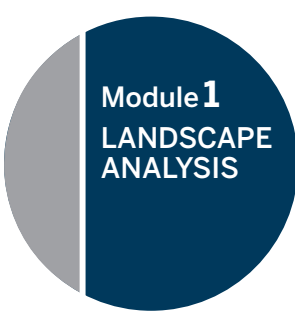

MODULE 1: LANDSCAPE ANALYSIS

An analysis of the overall context of the HIV epidemic, along with a policy and HIV program scan, is an important first step. This analysis consists primarily of a desk review of available literature and data, supplemented as needed with input from experts familiar with the HIV epidemic and the specific country context. It will serve as a starting point and foundation for the process in Modules 2 and 3.

\section{MODULE 2: KEY OPINION}

LEADER AND DECISIONMAKER DISCUSSION GUIDE

Another key component involves conducting in-depth interviews (IDIs) with a select group of key opinion leaders (KOLS) who will be involved in or influence strategic decisions about the introduction of new ARV-based prevention products. Such KOLs can be identified from the "Potential Key Informants and Organizations" box (see page 4). IDIs should be conducted by a senior leader who is knowledgeable about both HIV prevention and the country's policy environment. Results will point to the strategic role a given product could play within a country's HIV-prevention program and help determine a plan for introduction.

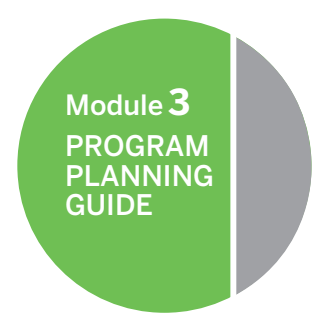

MODULE 3: PROGRAM PLANNING GUIDE

After gathering input from KOLs, a facilitated workshop should be convened that includes policymakers, service providers, and program managers who are responsible for implementing HIV-prevention programs. Module 3 is designed to stimulate discussion among these invited groups.

\section{APPENDIXES}

Appendix 1 contains key guidelines and reference materials.

Appendix 2 provides a detailed sample workshop agenda.

Appendix 3 includes a checklist that will assess the readiness of service-delivery points for product delivery. 


\section{GETTING STARTED}

A small, in-country team will be needed to manage the process. The team should include individuals with the following attributes:

- An appropriate mix of skills and a professional reputation to engage key decisionmakers and program leaders, and to ensure follow-up;

- In-depth knowledge of the country's health system and its HIV-prevention program(s);

- Access to relevant professional networks;

- Technical expertise with the specific product and any associated service components.
Completing this process will equip the team with the elements needed to develop an introduction plan that defines:

- The strategic rationale for introducing a specific new product;

- Target populations to be served;

- Potential entry points and service settings for offering the product;

- Steps and resources required to move forward at a program level.

\section{POTENTIAL KEY INFORMANTS AND ORGANIZATIONS TO GUIDE} THE INTRODUCTION PLAN

- Policy decisionmakers and program planners

- Directors of HIV/AIDS, health, finance, and other related directorates

- Program directors from within health or other ministries

- Leaders of HIV/AIDS coordinating mechanisms

- Program managers, supervisors, and/or providers of clinical, primary, and community health care (see list of settings, right)

- Managers of commodity security and logistics

- Key training institutions

- Nongovernmental, faith-based, private, and professional organizations, particularly those focused on HIV-related services

- Advocates for women and for vulnerable and at-risk populations

- Social marketing groups

- Development partners, including donors and technical-assistance agencies
POTENTIAL SERVICE SETTINGS

FOR DELIVERING NEW ARV-BASED PREVENTION PRODUCTS

- Public-sector health centers

- HIV-counseling and testing sites - Family planning/reproductive health/ STI prevention and treatment services

- Maternal health settings, including antenatal care

- Prevention programs for sero-positive and sero-discordant couples

- Programs for vulnerable and most-at-risk populations (MARPs)

- University-based health clinics and other services designed to reach young people (particularly girls and young women) 
This module will facilitate the creation of a landscape analysis of the HIV epidemic in a particular country.

The landscape analysis consists primarily of a desk review, supplemented as needed and as possible with expert opinion and interviews with key informants. The analysis and synthesis will provide an overview of the nature and shape of the HIV epidemic in the country as well as a general overview of the policy environment and structure of the country's health system.

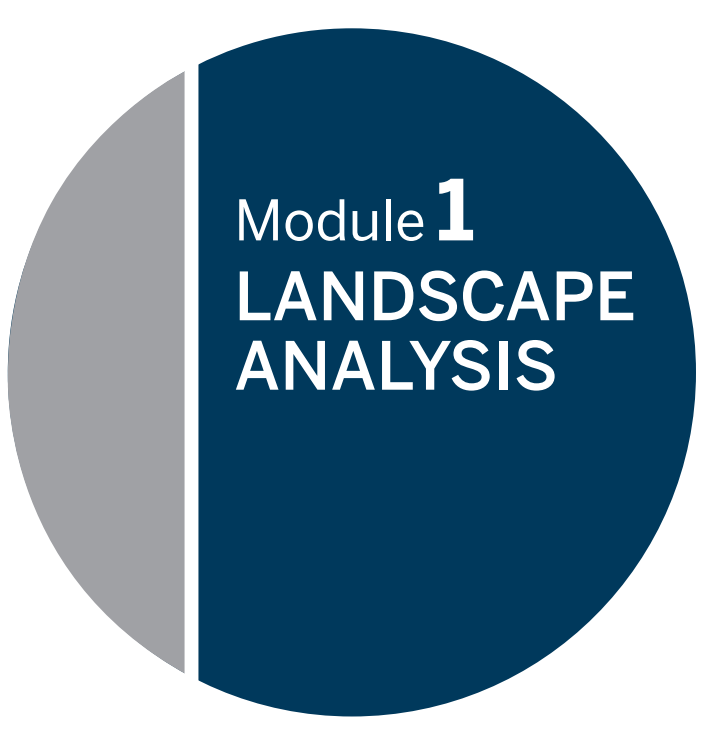

The desk review relies primarily on existing datasets and publicly available information from credible and referenced sources (for example, Demographic and Health Surveys, UNAIDS HIV country profiles, country-specific plans and updates, if relevant). See Appendix 1 (Key Guidelines and Reference Materials) for additional sources. The information should be presented in brief narrative and tabular form, with sources and citations provided. The output should include a summary with citations, data tables, appendixes of key documents, and other reference materials, as appropriate. 


\section{EPIDEMIOLOGICAL CONTEXT}

(1) Describe the country's HIV epidemic. Use:

- National prevalence/incidence (stratified by age, gender, state/province/district)

- Trends in prevalence/incidence (stratified by age and gender)

- Populations with highest prevalence/incidence

- Coverage of antiretroviral therapy

- Important risk factors for women

- Age at first sex

- Age at marriage

- Concurrent sexual partnership patterns

- Intimate partner violence

- Most-at-risk populations (MARPs; defined in country context)

(2) Describe results of Modes of Transmission Studies (MTS), if available.

(3) Describe current contraceptive use patterns.

- Contraceptive prevalence (by age and region)

- Method mix; most commonly used method(s) (by age and region)

\section{POLICY ENVIRONMENT}

(4) Describe the country's current HIV policies.

- Which HIV-prevention approaches, including technologies (e.g., reducing number of partners, abstinence, oral pre-exposure prophylaxis [PrEP], voluntary medical male circumcision [VMMC]) are included in relevant policies? Which approaches are emphasized in which policies and for which user groups?

- Describe service guidelines and protocols (and include in an accompanying Appendix, if available) specifically geared toward:

- HIV-prevention programs

- HIV-treatment programs

- HIV and family planning/reproductive health integration

(5) Is there documentation of any experiences regarding technology introduction in the country that can help inform the introduction of ARVbased prevention for women?

- regarding male or female condoms, reproductive health products, or antiretroviral therapy [ART], for example

If yes, summarize key lessons from these experiences. 
(6) Which policies, regulatory authorities, and agencies are involved in the approval and introduction of new HIV or reproductive health products?

(7) Describe current policies, laws, and servicedelivery guidelines regarding the initiation, dispensing, and resupply of ARV-containing products.

(8) List any restrictions on HIV or SRH services. Are they based on:

- Age

- Marital status

- Laws affecting key groups (sex workers injecting drug users, men who have sex with men, etc.)

(9) List any antidiscrimination laws protecting people living with HIV.
(10) What is the breakdown of funding for HIV-treatment and prevention programs in the country?

- Note the approximate proportion of funding for HIV treatment and prevention that comes from different sources (e.g., national, provincial government, donor organizations, private sector, faith-based organizations, communication resources, individual/family out-of-pocket).

- Note the roles that public/private partnerships and/ or social marketing play.

- Note the proportion of HIV expenditures by commodities and programming for treatment and for prevention, if available.

(11) Provide recent statistics (national, provincial, district) on use of these services, if available.

- HIV-treatment services

- HIV-prevention services (medical male circumcision, prevention of mother-to-child transmission postnatal care, post-exposure prophylaxis)

- Antenatal care

- HIV counseling and testing

- Family planning

- Adolescent-related services

- STIS

- Other relevant services 
(12) Which sector-public, nongovernmental organization (NGO), or private-generally takes the lead on new health innovations and approaches?

\section{STRATEGIC OPPORTUNITIES}

(13) Based on the available information and analysis, what are the main strategic opportunities for introducing ARV-based prevention for women? What are the main challenges?

(14) Are there any national initiatives that are ongoing or to be launched that may have a bearing on the introduction and financing of new products (e.g., National Health Insurance schemes, voucher systems, re-engineering of primary health care)?

(15) List other key insights or suggestions for research, policy, or programming to initiate ARVbased prevention for women. 
This module is designed to engage key decisionmakers who will be involved in or influence strategic decisions regarding the introduction of antiretroviral (ARV)-based prevention products for women.

By exploring views and eliciting expert opinions, this module identifies key questions and issues that must be considered and addressed to inform decisions about introducing new products in the context of a country's specific HIV epidemic, health system, and political and economic environment.

Module 2 is structured as a questionnaire intended to guide individual in-depth interviews (IDIs) with carefully selected
Module 2 KEY OPINION LEADER AND DECISIONMAKER DISCUSSION GUIDE

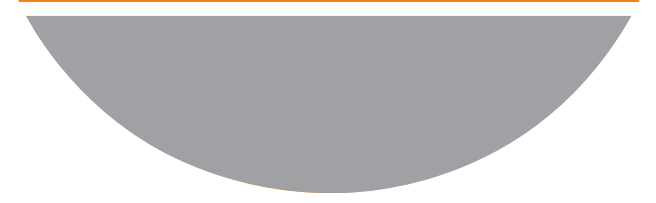

key opinion leaders and decisionmakers. The IDIs are conducted by a senior leader working in the HIV field. As such, it assumes a fairly high level of knowledge and awareness of critical issues in HIV prevention and of the policymaking environment in the country. The guide considers scientific, political, and economic factors that drive decisionmaking and general issues related to health-system capacity.

This tool is flexible and can be adapted for use in discussing a wide range of ARV-based prevention products for women, such as the dapivirine intravaginal ring (IVR), Truvada for oral pre-exposure prophylaxis (PrEP), and other emerging technologies. 


\section{SCIENTIFIC EVIDENCE}

(1) What scientific evidence would be needed to make a decision to introduce [insert specific product] in the country? [Probe, as needed:]

- Safety data

- In the general population

- In pregnant women

- During breastfeeding

- In adolescents

- Impact on current and future fertility

- Effectiveness/level of efficacy (how well it works)

- Acceptability (and adherence)

- Potential resistance

(2) How should the data be made available to decisionmakers (e.g., results of randomized controlled trials, journal articles, briefings)? What source of data would support the decisionmaking process?

\section{TARGET POPULATIONS}

The introduction of a new HIV-prevention product can increase options for individuals to reduce their risk of infection and holds the potential for a broader public health impact.

(3) In your view, who will benefit most from using [insert specific product]? Why? In which situations? [Probe, as needed:]

- Sero-discordant couples

- Young women

- Married women (Married women whose husbands work away from home)

- Sex workers

- Women who have infrequent but risky sex (e.g., exchange sex for money, food, shelter)

- Women who have multiple partners

- Women whose partners have multiple partners

(4) Where do you see_[insert specific product] fitting into the country's HIV-prevention program vis-à-vis existing strategies?

(e.g., HIV counseling and testing, voluntary medical male circumcision (VMMC), oral PrEP, condom promotion, behavior-change communications)?

(5) How would you prioritize _[insert specific product] relative to other HIV-prevention strategies and why? 


\section{IMPACT ON HEALTH SYSTEMS}

6) What are the potential opportunities for delivering_[insert specific product] ? Through which sectors and in which programs or services could this occur? [Probe, as needed:]

- Public vs. NGO vs. private sector

- Type of service

- Primary

- Secondary

- Tertiary

- Type of program

- ARV treatment

- HIV testing and counseling

- Voluntary medical male circumcision

- Sexual and reproductive health

- Antenatal care

- Family planning

- Well-baby

- Other

(7) If [insert specific product] was introduced in the country, what would be the implications for existing programs, services, and health systems? [Probe, as needed:]

- HIV-testing programs

- HIV-treatment programs

- SRH programs/services

- Staff deployment, task-shifting
(8) Are there lessons (positive and negative) from the introduction of other technologies or prevention strategies that could inform plans for introducing _[insert specific product] ?

\section{POLICY CONSIDERATIONS}

(9) What do you see as the potential benefits and risks from introducing [insert specific product] ? [Probe, as needed:]

- Expanded options for prevention

- Equity

- Reactions from various constituencies-religious, community, advocacy groups

(10) Who are the key players (organizations) that must be engaged in the decision about whether to introduce [insert specific product] ?

[Probe, as needed:]

- Regulatory bodies (local and international)

- Guidelines from normative agencies (WHO, etc.)

- Others

(11) Are there champions for ARV-based prevention or HIV prevention for women in the country who could help advocate for _[insert specific product]? 


\section{ECONOMICS, COST, AND FINANCING}

Cost considerations, including manufacturing, often factor heavily in decisions about whether, how, and at what scale new health products should be produced and introduced. Many of these are influenced nationally and globally.

(12) How would the decision be made whether to invest in introducing _ [insert specific product] ?

(13) What would you or other decisionmakers need to know to make the investment case for _ [insert specific product] in order to allocate a budget for product procurement and introduction?

(14) How do you think this product could be financed in the short term? The long term?

(15) How could supplying _ [insert specific product] to those who need it be sustained over the long term?

(16) From your experience, can you comment on key issues to consider related to the following:

- Product-procurement mechanism

- Supply chain

- Manufacturing

- Pharmaco-vigillance/surveillance

\section{DECISIONMAKING}

(17) If you were asked to make a decision today about whether to introduce _[insert specific product] , what would you do? Why?

(18) From your position and the role that you/your agency plays, what other information/data would you need to make a decision about introducing [insert specific product] ?

(19) Is there anything else you would like to add? 
This module is designed to stimulate discussion among selected service providers, policymakers, and program managers who are responsible for implementing HIV-prevention programs.

The module provides key questions that can be addressed through facilitated group discussions in a workshop format (a sample agenda is provided in Appendix 2). This module leads participants through a series of service-design considerations that need to be addressed in program planning. The outcome of this process is a plan for product introduction that supports quality services and clients' rights.

\section{Module 3 \\ PROGRAM PLANNING GUIDE}

\section{POLICY ENVIRONMENT}

(1) How are new HIV-prevention methods incorporated into national HIV policies and strategic plans?

(2) How are priorities set for HIV prevention and treatment programs, and at what level of the health system (national, provincial, or district)?

(3) Which HIV-prevention approaches are emphasized in current plans? Are different approaches emphasized for different user groups? 


\section{TARGET POPULATIONS}

(4) In your view, what populations would benefit most from this product? [Probe, as needed:]

- Sero-discordant couples

- Young women

- Married women

- Sex workers

- Women who have infrequent but risky sex (e.g., exchange sex for money, food, shelter)

- Women who have multiple partners

- Women whose partners have multiple partners

(5) For each group that would benefit, where and how would they best be reached?

\section{MESSAGING AND DEMAND CREATION}

(6) Which organization is charged with developing and/or maintaining messages for HIV prevention generally? For ARV-based prevention for women in particular?

(7) Describe key campaigns that are focused on HIV prevention for women. How were they developed? How would new ARV-based prevention products or services for women be best incorporated into these campaigns?
(8) Which channels do these campaigns use? Which do you think are most effective?

- Mass media

- Peer education

- Clinic-based information, education, communication

- Community education

- Mobile and digital media

(9) Do you have ideas about how best to create demand for this new product?

(10) What specific lessons can be applied from other technology-introduction efforts?

(11) What do you anticipate will be the key barriers for women who wish to use the product?

(12) How can existing programs be capitalized upon to support introduction? 


\section{SERVICE PROVISION}

13) How well do you think HIV prevention is currently integrated with these other health programs and services?

- Reproductive health

- Child health

- Primary health

(14) ARV-based prevention products will require counseling, HIV testing, and monitoring. Which service settings might afford good opportunities for delivering this product? [Probe, as needed:]

- HIV counseling and testing (HCT)?

- Family planning?

- School-based programs (adolescents)?

- Antenatal care?

- Services for sero-discordant couples?

- Sexually transmitted infection services?

- Primary health?
(15) In the settings that have been identified as favorable for integrating ARV-based prevention for women, are facilities generally adequate?

Consider whether:

- Essential supplies/commodities (including HIV tests) are routinely available

- Facilities have patient-education materials on ARVbased prevention to support community- and clinicbased education

- Facilities are able to handle specific commodity requirements (storage space, shelf life, temperature, stock control, security, expiration)

(16) Is staffing generally adequate?

- Given resource constraints, how might services be provided and by whom?

- Can you envision assigning clinic staff to the specific task of providing clients with, and counseling them on, this product?

- Would there be opportunities for training different cadres of staff in ARV-based prevention and counseling?

(17) How do existing human resource training strategies incorporate:

- HIV-prevention approaches?

- Family planning/reproductive health?

- HIV treatment, counseling, and care?

- Are there specific training materials or curriculums that could be adapted to include ARV-based prevention for women? 
(18) What staffing will be needed to support the introduction of a new ARV-based prevention product for women?

- Which cadres of health personnel (e.g., nurses, physicians, counselors, health officers)?

- At which levels of the health system (district, province, community)?

(19) What do you foresee as the key challenges providers may face in offering ARV-based prevention products for women?

\section{COMMODITIES/SUPPLY CHAIN/LOGISTICS}

(20) Is there an effective commodity-security program (for HIV and/or reproductive health commodities) that currently exists and could be used for new HIV-prevention products? If not, what areas of the supply chain require strengthening?
(21) What commodities are currently available for HIV prevention (e.g., HIV test kits, male condoms, female condoms)? And:

- Who provides them?

-Who pays for them (e.g., national government, donor agencies)?

-What client fees or cost-sharing is levied on these commodities?

- How would a new product be added to the HIV commodities-procurement list?

- What do you think will be the challenges regarding procurement and supply of ARV-based products?

\section{IMPLICATIONS/SPECIAL CHALLENGES}

22. Do you have any concerns related to an ARV-based prevention product that uses the same active drug used in treatment regimens?

- Real or perceived tension between resources for treatment and prevention?

- Potential resistance?

(23) Are there systems for post-marketing surveillance and pharmaco-vigilance that can be used to track HIV resistance, adverse events, or side effects related to ARV-based prevention products? 
Appendixes 


\section{Appendix 1 Key Guidelines and Reference Materials}

The key guidelines found in the toolkits and manuals listed below have been produced by collaborating agencies and other major institutions known for their work within the fields of HIV/AIDS and sexual/reproductive health.

Bristol-Myers Squibb Foundation, Southern Africa HIV Clinicians Society and International Training and Education Center on HIV (I-TECH) 2007. "Secure the future manual: Seven steps to involve the community in HIV/AIDS treatment support programmes, first edition." New York: Bristol-Myers Squibb Foundation. http://www.securethefuture.com/our_ experience/STF_manual_first_edition.pdf

Farrell, Betty L. 2007. “Family planningintegrated HIV services: A framework for integrating family planning and antiretroviral therapy services." New York: EngenderHealth/ ACQUIRE Project. http://www.acquireproject. org/fileadmin/user_upload/ACQUIRE/

Publications/FP-HIV-Integration_framework_ final.pdf

FHI360. 2008. "Increasing access to contraception for clients with HIV: A toolkit." Research Triangle Park, NC: FHI360. http://www.fhi360. org/training/en/modules/FPHIV_toolkit/ interface.pdf

Futures Group. 2000. "The AIDS impact model (AIM) approach." Washington, DC: Futures Group/POLICY Project. http://www. policyproject.com/pubs/bookgreen.pdf
International AIDS Vaccine Initiative (IAVI). 2009. "Integrating gender issues into AIDS vaccine clinical research: A training manual for SubSaharan Africa." New York. http://www.iavi.org/ Lists/IAVIPublications/attachments/ c92467a3-8da3-4c83-8ba2-2520acf93518/ IAVI_Integrating_Gender_Issues_into_AIDS_ Vaccine_Clinical_Research_2009_eng.pdf

International HIV/AIDS Alliance. 2010. “Integration of HIV and sexual and reproductive health and rights: Good practice guide." Brighton, UK. http://www.aidsalliance.org/includes/ Publication/SRHGPG2.pdf

John Snow, Inc. (JSI). 2009. "Quantification of health commodities: A guide to forecasting and supply planning for procurement." Arlington, VA: JSI-USAID DELIVER Project, Task Order 1. http://sc4ccm.jsi.com/Docs/ QuantHealthCommunity.pdf

Joint United Nations Programme on HIV/AIDS (UNAIDS). 2011. "Joint strategic action framework to accelerate the scale-up of voluntary medical male circumcision for HIV prevention in Eastern and Southern Africa." Geneva: UNAIDS. http://www.unaids.org/en/media/ unaids/contentassets/documents/unaids publication/2011/JC2251_Action_Framework_ circumcision_en.pdf
K4Health. 2014. "Microbicides toolkit." Research Triangle Park, NC: FHI360. http://www. k4health.org/toolkits/microbicides

MacQueen, Kathleen and Mike May. 2008. "Partnering for care in HIV prevention trials: A how-to manual." Research Triangle Park, NC: FHI360. http://www.fhi360.org/resource/ partnering-care-hiv-prevention-trialshow-manual

Patel, A. et al. 2010. "Pediatric HIV treatment toolkit: A practical guide to the implementation of the 2009 World Health Organization pediatric HIV treatment recommendations." Arlington, VA: USAID AIDSTAR-One Project, Task Order 1. http://www.aidstar-one.com/sites/ default/files/AIDSTAR-One_HIV_Pediatric_ Treatment_Toolkit.PDF

Raney, Laura et al. 2008. "Balanced counseling strategy plus user's guide," in The Balanced Counseling Strategy Plus: A Toolkit for Family Planning Service Providers Working in High STI/HIV Prevalence Settings. Washington, DC: Population Council. http://www.popcouncil. org/pdfs/frontiers/Manuals/BCSPlus/BCSPlus_UsersGuide.pdf 
Robinson, Elizabeth T. et al. 2010. "Communications handbook for clinical trials: Strategies, tips, and tools to manage controversy, convey your message, and disseminate results." Research Triangle Park, NC: FHI360/ Contraceptive and Reproductive Health Technologies Research and Utilization Program. http://www.fhi360.org/resource/ communications-handbook-clinicaltrials-strategies-tips-and-tools-managecontroversy-convey

Ross, John and Ellen Smith. 2010. “The family planning effort index: 1999, 2004, and 2009." Washington, DC: Futures Group/ Health Policy Initiative. http://www. healthpolicyinitiative.com/Publications/ Documents/1110_1_FP_Effort_Index_1999_ 2004_2009_FINAL_05_08_10_acc.pdf

Sanders, Rachel, Karen Hardee, and Carol Shepherd. 2007. "Implementing integrated family planning and HIV/AIDS policies and programs: Tools and resources." Washing- ton, DC: Futures Group/POLICY Project. http://www.policyproject.com/pubs/ generalreport/ImplementingPoliciesand Programs.pdf

USAID, Center for Accelerating Innovation and Impact (CII). 2015. "Idea to impact. A guide to introduction and scale of global health innovations." Washington, DC: CIl. http:// www.usaid.gov/cii/guide-introductionand-scale

World Health Organization (WHO). 2004.

"A guide to rapid assessment of human resources for health." Geneva: WHO. http://www.who.int/hrh/tools/en/ Rapid_Assessment_guide.pdf

- - - 2009. "Integrating gender into HIV/ AIDS programmes in the health sector:

Tool to improve responsiveness to women's needs." Geneva: WHO. http://www.who.int/ gender/documents/gender_hiv guidelines_en.pdf
WHO, International HIV/AIDS Alliance, and PharmAccess International. 2003. "A public health approach for scaling up antiretroviral treatment: A toolkit for programme managers." Geneva: WHO. http://www.who.int/hiv/ pub/prev_care/arvtoolkit_en.pdf

WHO, United Nations Population Fund, UNAIDS, and International Planned Parenthood Foundation. 2005. "Linking sexual and reproductive health and HIV/AIDS: An annotated inventory." Geneva: WHO. http:// www.who.int/hiv/pub/prev_care/inventoryfinal.pdf 


\section{Instrument Name}

Assessing Integration Methodology (AIM)

www.popcouncil.org/pdfs/frontiers/ Manuals/AIM.pdf

\section{COPE ${ }^{\circledR}$ for HIV Care and Treatment Services: A Toolbook to Accompany the COPE ${ }^{\circledR}$ Handbook}

www.engenderhealth.org/files/pubs/qi/ cope_hiv_care_treatment.pdf

Decision Makers' Program Planning Tool (DMPPT): Calculating the Costs and Impacts of a Male Circumcision Program

http://www.malecircumcision.org/ resource/decision-makers\%E2\%80\%99program-planning-tool-dmppt-manual

\section{Decision-making Tool for Family}

Planning Clients and Providers + Technical Adaptation Guide

whqlibdoc.who.int/publications/ 2005/9241593229_eng.pdf

www.who.int/reproductivehealth/

publications/family_planning/Technical_ adaptation_guide.pdf

Demographic and Health Surveys Service Provision Assessments (DHS SPA)

www.dhsprogram.com/What-We-Do/ Survey-Types/SPA.cfm
Health Policy

Initiative-

Futures/UNAIDS

\section{Developer}

FRONTIERS-

Population Council

EngenderHealth

Date

2008

IN

\section{INFO Project- $\mathrm{JHU} / \mathrm{CCP}$ and WHO}

\section{Measure DHS}

Multiple
years

\section{Description}

Can be used by decisionmakers to assess the feasibility of linking services, identify programmatic or structural barriers to integration, pilot-test approaches to integrating services, evaluate effects of linked or integrated services, and assess/evaluate costs of integrated services models.

Provides materials for identifying and solving onsite problems that compromise the quality of HIV care and treatment services. The tools address:

informed consent, confidentiality, clinical management of HIV, provision of ART, positive prevention, and integration of SRH and HIV services.

2009 This tool was developed to enable decisionmakers to understand the potential cost and impact of various options for scaling up male circumcision services within their particular country setting.

Designed for use by family planning providers to help clients make informed choices about contraceptive methods and to give clients the information and help they need to use their chosen method successfully. Adaptation guidelines provided for specific methods and contexts.

Offers a comprehensive overview of a country's health-care services and its capacity to provide quality care. SPA surveys examine the supply side of health care, showing the strengths and weaknesses of a country's public and private services. It focuses on five key services: child health, maternity and newborn care, family planning, STIs and other infectious diseases, and HIV/AIDS.

\section{Where Used/Tested}

Multiple country settings, including Bangladesh, Bolivia, Dominican Republic, Egypt, Ghana, Guatemala, India, Kenya, Nicaragua, South Africa, and Uganda.

Field-tested in Uganda. Used in multiple country settings.

\section{Botswana, Lesotho,} Namibia, Swaziland, Uganda, and Zambia

\section{Indonesia, Mexico,}

Nicaragua, South Africa, and Trinidad and Tobago.

\section{Multiple countries.}




\begin{tabular}{|c|c|c|c|c|}
\hline Instrument Name & Developer & Date & Description & Where Used/Tested \\
\hline $\begin{array}{l}\text { Facility Audit of Service Quality (FASQ) } \\
\text { ihfan.org/home/index.php?editable= } \\
\text { no\&page_type=catalog }\end{array}$ & $\begin{array}{l}\text { Measure } \\
\text { Evaluation }\end{array}$ & 2008 & $\begin{array}{l}\text { Provides information on types of service, status } \\
\text { and functionality of infrastructure, equipment, } \\
\text { and quality of care. It facilitates local (e.g., proj- } \\
\text { ect- or district-level) and low-cost monitoring of } \\
\text { availability and quality of facility-based reproduc- } \\
\text { tive and child-health services at government and } \\
\text { private facilities, including private clinics. }\end{array}$ & $\begin{array}{l}\text { Bangladesh, Bolivia, Kenya, } \\
\text { and Tanzania. }\end{array}$ \\
\hline $\begin{array}{l}\text { Health Facility Tool to Assess } \\
\text { Preparedness for HIV Service Delivery, } \\
\text { including Antiretroviral Therapy } \\
\text { www.aidsdatahub.org/sites/default/files/ } \\
\text { documents/Health_Facility_Tools_to_Assess_ } \\
\text { Preparedness_for_HIV_Services_Delivery_- } \\
\text { Including_Antiretroviral_Therapy.pdf.pdf }\end{array}$ & FHI360 & 2007 & $\begin{array}{l}\text { Tool is designed to help governments and } \\
\text { organizations determine availability/quality } \\
\text { of essential elements of HIV services, gather } \\
\text { necessary data about these services, and plan for } \\
\text { program implementation. }\end{array}$ & $\begin{array}{l}\text { Cambodia, Ethiopia, Kenya, } \\
\text { Nigeria, Rwanda, Senegal, } \\
\text { and Zambia. }\end{array}$ \\
\hline $\begin{array}{l}\text { HIV/AIDS Program Sustainability Analysis } \\
\text { Tool (HAPSAT): MoH Questionnaires } \\
\text { pdf.usaid.gov/pdf_docs/PNADX754.pdf }\end{array}$ & $\begin{array}{l}\text { Health } \\
\text { System 20/20- } \\
\text { Abt Associates }\end{array}$ & 2010 & $\begin{array}{l}\text { Developed to assist governments and donors with } \\
\text { the development of HIV/AIDS policies and imple- } \\
\text { mentation plans. }\end{array}$ & $\begin{array}{l}\text { Cote d'Ivoire, Guyana, } \\
\text { Haiti, Kenya, Nigeria, Sierra } \\
\text { Leone, South Sudan, and } \\
\text { Zambia. }\end{array}$ \\
\hline $\begin{array}{l}\text { Paving the Path: Preparing for } \\
\text { Microbicide Introduction } \\
\text { www.engenderhealth.org/files/pubs/ } \\
\text { hiv-aids-stis/paving_the_path.pdf } \\
\text { (Report only. Tools available upon request.) }\end{array}$ & $\begin{array}{l}\text { EngenderHealth, } \\
\text { International } \\
\text { Partnership for } \\
\text { Microbicides, UCT } \\
\text { Women's Health } \\
\text { Research Unit, } \\
\text { Population Council }\end{array}$ & 2004 & $\begin{array}{l}\text { A review was conducted of instruments that were } \\
\text { used in this study to explore and identify issues } \\
\text { that could facilitate or undermine access to and } \\
\text { use of microbicides. }\end{array}$ & South Africa. \\
\hline $\begin{array}{l}\text { What Is the Policy Environment Score } \\
\text { (PES)? } \\
\text { www.policyproject.com/policycircle/ } \\
\text { content.cfm?aO=3f }\end{array}$ & $\begin{array}{l}\text { Policy Project- } \\
\text { Futures }\end{array}$ & 1997 & $\begin{array}{l}\text { Designed to measure the overall status of the } \\
\text { policy environment for SRH, FP, adolescent RH, } \\
\text { HIV/AIDS, safe motherhood, and PAC in a particular } \\
\text { country, evaluating changes in the policy environ- } \\
\text { ment over time and identifying those areas most } \\
\text { in need of improvement. }\end{array}$ & $\begin{array}{l}\text { Jamaica, Jordan, Nigeria, } \\
\text { and Uganda. }\end{array}$ \\
\hline $\begin{array}{l}\text { QOC for Integrated Services - } \\
\text { Clinic Assessment Guide } \\
\text { www.pathfind.org/site/DocServer/QOC_ } \\
\text { document_oct_6.pdf?docID=1581 }\end{array}$ & Pathfinder & 2003 & $\begin{array}{l}\text { Enables those involved in health management } \\
\text { to collect detailed information on the range and } \\
\text { quality of integrated services available at a given } \\
\text { facility and thus to facilitate the design of more } \\
\text { effective program interventions. }\end{array}$ & Nigeria. \\
\hline
\end{tabular}




\section{Instrument Name}

Rapid Assessment Tool for Sexual and Reproductive Health and HIV Linkages

whqlibdoc.who.int/hq/2009/91825 eng.pdf

SEED ${ }^{T M}$ Assessment Guide for Family Planning Programming

www.engenderhealth.org/seed

Tool to Assess Site Readiness for Initiating Antiretroviral Therapy (ART) or Capacity

for Existing ART Sites, Version 1.3

deliver.jsi.com/dlvr_content/resources/

allpubs/guidelines/ToolAsseSiteRead.pdf

\section{Developer}

PFP, UNFP, WHO

UNAIDS, et al.

EngenderHealth

Date

2009

Can be used to assess links between HIV and SRH at policy, program, and facility levels, and ulti-

mately contribute to the development of country

specific action plans to forge and strengthen linkages.

Designed to help determine strengths and weaknesses in FP programs by identifying gaps that require further investment or more in-depth assessment prior to (re)designing interventions.

John Snow, Inc

2007 (JSI)

This tool was designed to provide sites and pro grams with a set of criteria to assess a site's readiness to implement ART or the current capacity and needs of an existing program, and to identify key areas that need strengthening.

19 countries in Africa, Asia, Central America, and the

Russian Federation.

Burkina Faso, Mali, Nigeria,

Rwanda, Senegal, and

Togo.

Field tested in Zimbabwe. Used in multiple country settings. 


\section{Appendix 2 Sample Agenda}

This sample details a facilitated discussion on program planning for tenofovir gel introduction. The agenda is based on Module 3: Program Planning Guide and outlines how a 1- or 11/2-day workshop could be convened with country stakeholders to explore program implementation issues. Specific approaches to facilitation and the time allotted for each section will depend on the context, the size of the group, and attendees' backgrounds.

\begin{tabular}{|c|c|}
\hline \multicolumn{2}{|r|}{ PROGRAM PLANNING FOR TENOFOVIR GEL INTRODUCTION } \\
\hline $\begin{array}{l}\text { SESSION } 1 \\
(0.5 \text { hour })\end{array}$ & $\begin{array}{l}\text { Introduction } \\
\text { Welcome, participant introduction, purpose of meeting }\end{array}$ \\
\hline $\begin{array}{l}\text { SESSION } 2 \\
\text { (1.5 hours) }\end{array}$ & $\begin{array}{l}\text { Purpose: Ensure that all participants share a common understanding } \\
\text { about tenofovir gel as well as technical and contextual factors related } \\
\text { to its introduction. }\end{array}$ \\
\hline & $\begin{array}{l}\text { Setting the stage (plenary presentations by technical experts): } \\
\text { - Technical update on tenofovir gel (expert slides will be provided, } \\
\text { detailing mechanism of action, status of clinical trials and } \\
\text { research, and key issues for service delivery) } \\
\text { - Summary of results of landscape analysis (Module 1) } \\
\text { - Summary of results from interviews with key opinion leaders and } \\
\text { decisionmakers (Module 2) }\end{array}$ \\
\hline & -break- \\
\hline $\begin{array}{l}\text { SESSION } 3 \\
\text { (1.5 hours) }\end{array}$ & $\begin{array}{l}\text { Purpose: Participants consider the information from the previous } \\
\text { session to identify strategic roles that tenofovir gel could play. }\end{array}$ \\
\hline & $\begin{array}{l}\text { Small-group discussion: What role could tenofovir gel play in the } \\
\text { country? } \\
\text { - Break participants into small groups mixed by discipline } \\
\text { (policymakers, managers, providers) } \\
\text { - Ask groups to consider key questions from Module 3, such as: } \\
\text { - Based on the HIV epidemic in the country, who do you think } \\
\text { will most benefit from tenofovir gel? } \\
\text { - Based on the country's health-system capacity, which } \\
\text { service settings afford good opportunities for implementing } \\
\text { tenofovir gel? } \\
\text { - What do you think will be the key barriers/obstacles for women } \\
\text { who wish to access tenofovir gel? } \\
\text { - What key challenges might providers face in providing } \\
\text { tenofovir gel? } \\
\text { - Report back in plenary; facilitator synthesizes input to develop a goal } \\
\text { statement that can guide tenofovir gel introduction. }\end{array}$ \\
\hline
\end{tabular}

SESSION 4 Purpose: Participants examine specific program components (1.5 hours) to identify issues that must be included in a program plan.

Small-group discussion: What opportunities and challenges should be addressed in a program plan for tenofovir gel introduction?

- Break into four groups, ensuring that each includes at least two participants with expertise in the discipline related to the specific program component being discussed:

- Policy environment

- User perspectives and demand creation

- Service provision

- Commodities, supply chain, and logistics

- Ask participants to review selected questions from Module 3 related to these topics

- Report back in plenary; facilitator to synthesize key issues to address in introduction and implementation.

$$
\text { -break- }
$$

SESSION 5 Purpose: Discuss special issues and challenges related to (1 hour) tenofovir gel.

Expert panel discussion: What are some key implications and special challenges for introducing tenofovir gel?

- A panel of in-country and international experts highlight selected issues from Module 3 about the impact tenofovir gel could have on HIV testing, potential resistance, and prevention options/method mix for HIV prevention, followed by a facilitated discussion and brainstorming with all participants to identify implications and issues.

SESSION 6 Purpose: Summarize key points from the discussions, identify (0.5 hour) and prioritize next steps.

Conclusions and next steps: The way forward

$$
\text { -adjourn- }
$$




\section{Appendix 3 A Checklist for Service-Delivery Readiness}

This checklist is intended for use by program managers and health providers to determine the readiness of service-delivery points to deliver ARV-based prevention for women. The checklist is administered through direct observation by trained observers and/or researchers and can be used to: 1) identify key areas requiring attention prior to initiating ARV-based prevention services; or 2) support the monitoring of related services once a product is introduced. The checklist promotes high-quality services and interactions between client and provider and is divided into two sections:
- SECTION I reviews overarching operations and facility-level components necessary for safe and effective product delivery

- SECTION II reviews staffing/human resource and provider components essential to deliver the product and to support provider-client interaction that ensures informed choice and decisionmaking concerning product adoption.

The checklist should be updated and revised once service-delivery guidelines and protocols for a specific product are developed.

\section{SECTION I: \\ OPERATIONS, GUIDELINES, FACILITY-RELATED ELEMENTS}

1. Written medical guidelines, protocols, and standards for ARV-based prevention exist and are available at the site.

2. Facilities have the necessary equipment and supplies to provide the product, including (to be modified depending on specific product):

- HIV test kits

- Pelvic models (at training facilities)

- Other

3. A range of HIV-prevention options are available and in stock at the site.

4. The facility has adequate space to ensure confidential HIV testing and counseling.

5. The facility has adequate space and conditions (temperature and humidity control, security, etc.) to store the product.

6. The facility has a system to forecast supply (and resupply) requirements, and uses it to prevent stock-outs.

7. Client records are maintained and kept confidential.

8. The facility has guidelines and clear linkages to facilitate integrated

\section{Yes No Comments}
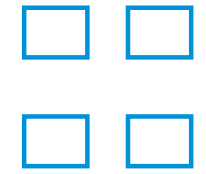

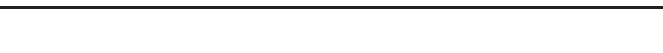
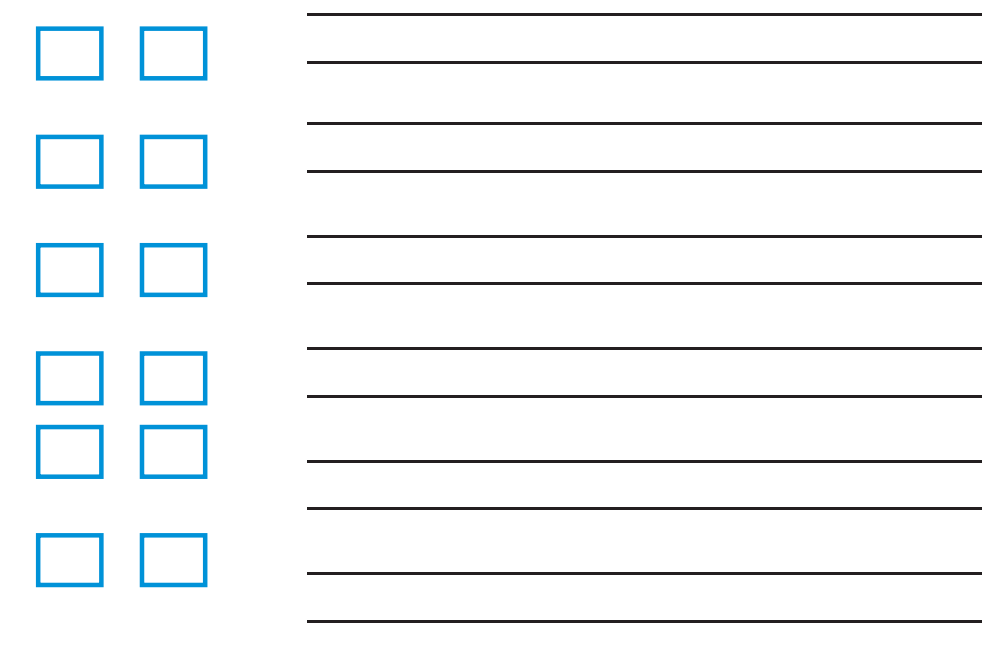


\section{SECTION II: \\ PROVIDER COMPETENCY, TRAINING, AND CLIENT INTERACTION}

1. Providers have been trained to provide ARV-based prevention for women.

2. Providers have job aids that include clear, up-to-date information about the product.

3. Providers follow protocols for infection prevention and safe disposal of medical waste.

4. A system is in place to periodically assess staff competency and training needs.

5. Providers counsel clients about HIV testing and retesting, and on all available HIV-prevention options.

6. Providers ask clients about their reproductive intentions and, if desired, counsel and provide contraception or refer clients.

7. Providers ensure client privacy and confidentiality.

8. Providers ensure that clients understand how the product works, including risks/benefits, side effects, effectiveness.

9. Providers give instructions to clients about how to use, care for, store, and dispose of product and related supplies.

10. Providers are respectful of clients and tailor their interaction to clients' needs, circumstances, and concerns.

11. Providers use language that clients understand and check to ensure comprehension.
Yes No Comments

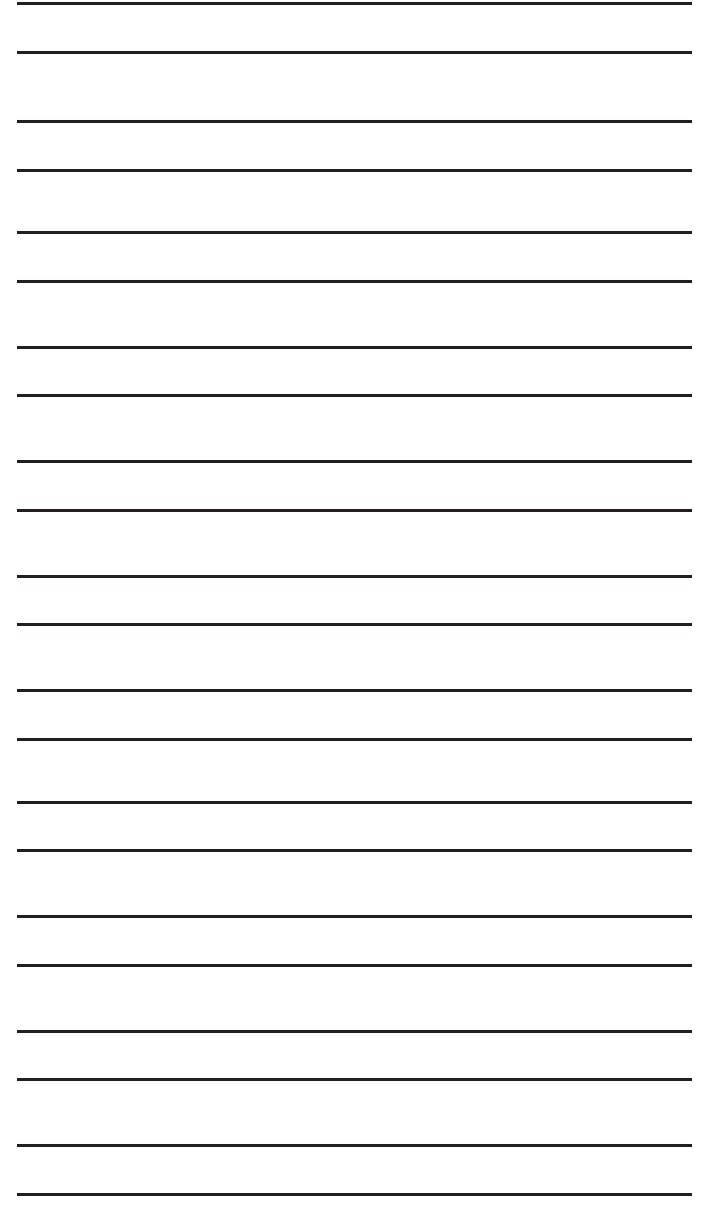


Notes 
Notes 




\section{POPULATION COUNCIL}

Ideas. Evidence. Impact.

One Dag Hammarskjold Plaza

New York, New York 10017 USA

Tel.: 212.339.0500

Fax: 212.755 .6052

popcouncil.org 